\title{
DISCUSSÃO DO LUGAR E ALFABETIZACÃO CARTOGRÁFICA NO ENSINO FUNDAMENTAL: A ELABORAÇÃO DE CADERNOS DIDÁTICOS ASSOCIADOS A ATLAS GEOAMBIENTAIS MUNICIPAIS DO CENTRO OESTE GAÚCHO
}

Franciele Delevati Ben

Universidade Federal de Santa Maria (UFSM) - Santa Maria, RS, Brasil

Graduanda em Geografia Licenciatura francielidelevattiben@gmail.com

Giorge Gabriel Schnorr

Universidade Federal de Santa Maria (UFSM) - Santa Maria, RS, Brasil Graduando em Geografia Licenciatura giorgeSchnorr@gmail.com

Carina Petsch Universidade Federal de Santa Maria (UFSM) - Santa Maria, RS, Brasil Professora Adjunta do Departamento de Geociências carinapetsch@gmail.com

Anderson Augusto Volpato Sccoti Universidade Federal de Santa Maria (UFSM) - Santa Maria, RS, Brasil Professor Adjunto do Departamento de Geociências asccoti2@gmail.com

Luis Eduardo de Souza Robaina Universidade Federal de Santa Maria (UFSM) - Santa Maria, RS, Brasil Professor Titular do Departamento de Geociências lesrobaina@yahoo.com.br

Romario Trentin Universidade Federal de Santa Maria (UFSM) - Santa Maria, RS, Brasil Professor Associado do Departamento de Geociências Romario.trentin@gmail.com

\section{RESUMO}

O conhecimento geográfico discutido pelo aluno em sala de aula, possibilita uma releitura do espaço vivido, onde processos físicos, que antes eram abstratos, recebem a luz da ciência e do conhecimento. O presente artigo tem como objetivo apresentar o processo de elaboração dos cadernos didáticos associados à Atlas Geoambientais do Centro-Oeste gaúcho. Além disso, é proposta a inserção das seis atividades, nas aulas de Geografia, segundo as recomendações da Base Nacional Comum Curricular. O artigo é baseado em um método descritivo e as atividades foram elaboradas para fomentar a alfabetização cartográfica dos alunos. Além disso, agregam conhecimentos acerca dos aspectos físicos e socioeconômicos e abordam discussões pautadas na relação sociedade e natureza. São discutidas as possíveis dificuldades que professores e alunos encontrarão ao interpretar os mapas, em especial, o Zoneamento Geoambiental. Baseada na percepção e sentidos dos alunos, discussões sistêmicas podem ser criadas e com isso a abstração do mapa Geoambiental que não é materializado no espaço vivido. No que se refere a elaboração do caderno didático, este material mostra um grande potencial para viabilizar a discussão do conteúdo cartográfico contido no Atlas Geoambiental, assim como para se trabalhar com as competências e habilidades exigidas pela BNCC.

Palavras-chave: Cartografia escolar. Atlas municipais. Cadernos didáticos. Espaço vivido. Leitura do espaço.

\section{DISCUSSION OF PLACE AND CARTOGRAPHIC LITERACY IN FUNDAMENTAL EDUCATION: THE ELABORATION OF DIDACTIC NOTEBOOKS ASSOCIATED WITH MUNICIPAL GEO-ENVIRONMENTAL ATLAS OF CENTRO OESTE GAÚCHO}

\section{ABSTRACT}

The theoretical knowledge discussed by the student in the classroom, allows a rereading of the lived space, where physical processes, which were previously abstract, receive the light of science and knowledge. This article aims to present the process of preparing the didactic book associated with Geoenvironmental Atlas of the Midwest of Rio Grande do Sul. In addition, it is proposed to insert six activities in Geography classes, according to the recommendations of the Common National Curricular Base of Brazil (BNCC, in portuguese). The article is based on a descriptive method and the activities were designed to promote students cartographic literacy. Furthermore, they add knowledge about the physical and

Caminhos de Geografia Uberlândia-MG $\quad$ v. 22, n. $83 \quad$ out./2021 p. 144-159 Página 144


Discussão do lugar e alfabetização cartográfica no ensino fundamental: a elaboração de cadernos didáticos associados a Atlas Geoambientais municipais do Centro Oeste Gaúcho
Franciele Delevati Ben

Giorge Gabriel Schnorr Carina Petsch Anderson Augusto Volpato Sccoti Luis Eduardo de Souza Robaina Romario Trentin

socioeconomic aspects, in addition to addressing discussions based on the relationship between society and nature. Also are discussed possible difficulties that teachers and students will find interpreting the maps, in particular, the Geoenvironmental Zoning. Based on the students' perception and senses, systemic discussions can be created and with that abstraction of the Geoenvironmental map that is not materialized in the lived space. About the didactic book, this material shows great potential to enable the discussion of the cartographic content in the Geo-Environmental Atlas, as well as to work with the competencies and skills required by the BNCC.

Keywords: School Cartography. Municipal atlases. Didactic books. Lived Space. Space Reading.

\section{INTRODUÇÃO}

A Geografia é a disciplina responsável por apresentar ao aluno, as explicações científicas dos processos e fenômenos que se desencadeiam em seu cotidiano. As experiências adquiridas pelo aluno em sala de aula, possibilita uma releitura do espaço vivido, onde processos físicos, que antes eram abstratos aos olhos do discente, recebem a luz da ciência e do conhecimento. Nesse sentido, os Atlas Municipais são importantes ferramentas que podem fomentar o ensino de Geografia voltado para a escala do lugar. Conforme Martinelli (2008) salienta, o conjunto de mapas possui representações de espaço mais próximas do aluno, em escala relativamente grande. Batista e Valente (2014) ressaltam que o estudo do lugar propicia, sobretudo, o desenvolvimento das noções de identidade e pertencimento, nos alunos.

Callai (2013) indica que é necessário interpretar o lugar buscando a articulação dos fatos, dos fenômenos e das forças. E Callai (2005, p.235) complementa que:

Do ponto de vista da Geografia, esta é a perspectiva para se estudar o espaço: olhando em volta, percebendo o que existe, sabendo analisar as paisagens como 0 momento instantâneo de uma história que vai acontecendo (Callai, 2005, p.235).

E para que o aluno seja capaz de fazer interpretações, analisar a paisagem e compreender a Geografia no seu cotidiano, Castelar (2000, p. 30) enfatiza que "é necessário criar condições para que a criança leia o espaço vivido". A leitura do espaço e a compreensão da Geografia, pelo aluno, ocorre necessariamente em conjunto com a Cartografia. Segundo Cavalcanti (1999), a Cartografia possui uma linguagem peculiar da Geografia, já que trata da forma de representar análises e sínteses geográficas, permite a leitura de acontecimentos, e a localização e explicação do porquê dessa localização, permitindo assim, sua espacialização.

Cavalcanti (2002, p. 16) salienta então sobre a Cartografia, que:

Não é um conteúdo a mais no ensino de Geografia; ele perpassa todos os outros conteúdos, fazendo parte do cotidiano da matéria. Os conteúdos de cartografia ajudam a responder àquelas perguntas: Onde? Por que este lugar? Ajudam a localizar fenômenos, fatos e acontecimentos estudados e a fazer correlações entre eles, são referências para o raciocínio geográfico (CAVALCANTI, 2002, p. 16).

Os alunos precisam ser estimulados ao longo de sua formação, a trabalhar com mapas, se orientar e se localizar, e entender os princípios da Cartografia. Almeida (2006) salienta que o aluno deve construir seu próprio conceito de mapa, ao entender o sistema de coordenadas, a escala, a projeção do espaço tridimensional sobre o plano em 2 dimensões do papel.

Bueno e Buque (2017) identificam a Cartografia como um elemento primordial para a construção de um Atlas, e além disso um instrumento que permite a construção de vários conceitos geográficos, com uma indiscutível importância no Ensino fundamental. Martinelli $(2008$, p. 24) ressalta que ao construir um atlas deve-se considerar o entrelaçamento de duas orientações básicas:

- o "ensino do mapa", lastreado nas posturas teórico-metodológicas sobre a construção da noção de espaço e respectiva representação pela criança;

- o "ensino pelo mapa", baseado na promoção do conhecimento do mundo através dos mapas, a partir do próximo, vivenciado e conhecido - o lugar - ao distante desconhecido - o espaço mundial (MARTINELLI, 2008, p. 24).

De acordo com Martinelli (2008), ao se executar o processo de elaboração de um Atlas para escolares, deve se considerar que esse não configure apenas um conjunto de produtos já finalizados, mas sim uma organização sistemática, baseada em temas com finalidades específicas. Além disso, 
Discussão do lugar e alfabetização cartográfica no ensino fundamental: a elaboração de cadernos didáticos associados a Atlas Geoambientais municipais do Centro Oeste Gaúcho
Franciele Delevati Ben

Giorge Gabriel Schnorr

Carina Petsch

Anderson Augusto Volpato Sccoti

Luis Eduardo de Souza Robaina Romario Trentin

os dados que compõem o Atlas devem ser atuais e confiáveis, possibilitando ao aluno uma maior assimilação das questões que se propõe, alcançando o máximo de conhecimento.

Sendo assim, o presente artigo tem como objetivo apresentar o processo de elaboração dos cadernos didáticos associados aos Atlas Geoambientais do Centro Oeste gaúcho. A elaboração dos cadernos didáticos, apresentando alguns exemplos de exercícios com base no Atlas Geoambiental, constituem uma tentativa de auxiliar e guiar o professor a trabalhar com o "lugar" na aula de Geografia, utilizando a representação de mapas do município e fomentar a construção e interpretação do espaço, pelos alunos. Além disso, é proposta a inserção das atividades, nas aulas de Geografia, segundo as recomendações da Base Nacional Comum Curricular - BNCC - (BRASIL, 2018).

\section{FUNDAMENTAÇÃO TEÓRICA}

\section{Cartografia Escolar e a elaboração do caderno didático}

É imprescindível tratar da elaboração de um Atlas e associá-la a Cartografia escolar, ou seja, como os alunos e professores irão ler um mapa. Segundo Almeida (2007), na interface da Cartografia, Educação e Geografia, surge a Cartografia escolar. Dessa forma, Passini (2007) define a Cartografia escolar como "uma proposta de transposição didática da cartografia básica e da cartografia temática para usuários do ensino fundamental, em que se aborde o mapa do ponto de vista metodológico e cognitivo".

Para compreender todas as informações representadas em um mapa, é necessária que haja a alfabetização cartográfica (PISSINATI e ARCHELA, 2007). Passini (2014, p. 743) define a alfabetização cartográfica como "o processo de desenvolvimento do domínio espacial, é uma proposta metodológica que considera o aluno um sujeito no espaço: vê e compreende, compreende e representa, representa e lê." Enquanto Simielli (1999), ressalta então que a alfabetização supõe o desenvolvimento de noções de: visão oblíqua e visão vertical; imagem tridimensional, imagem bidimensional; alfabeto cartográfico: ponto, linha e área; construção da noção de legenda; proporção e escala além da lateralidade/referências e orientação.

Ainda de acordo com Simielli (1999), há duas formas de se tratar a Alfabetização Cartográfica, com os alunos. A primeira maneira aborda o aluno leitor crítico, nessa abordagem o discente deve fazer a leitura sob uma perspectiva crítica, de mapas já prontos. O aluno mapeador consciente, é aquele onde os próprios sujeitos são os que elaboram os mapas, e estes necessitam, portanto, do entendimento do processo de elaboração do produto cartográfico.

Dessa maneira, é comum que os alunos sejam cobrados a interpretar mapas, porém os mesmos não foram alfabetizados para isso. Francischett (1997, p. 106), ressalta que "'cobrar' a leitura de um mapa é o mesmo que exigir de uma pessoa não alfabetizada, que leia fluentemente, sob pena de ser ridicularizada". Castrogiovanni (2008) complementa, e salienta que é um processo complexo, onde é necessário trabalhar com noções básicas de localização, organização, representação e compreensão dos espaços. E conforme Pissinati e Archela (2007), é preciso considerar a idade do aluno:

Para dar início à alfabetização cartográfica, o professor deve estar ciente das capacidades que a idade trabalhada possui e a experiência escolar e de vida que os alunos em questão já trazem. Alguns conceitos já podem ter sido assimilados pelos alunos nas séries anteriores, bastando apenas um reforço, enquanto outros ainda precisem ser introduzidos. Contudo, o professor jamais deve desprezar a bagagem que seus alunos têm e o esforço que eles fazem para compreender o conteúdo novo (PISSINATI e ARCHELA, 2007, p. 188).

Almeida e Passini (1994) ressaltam que o desenvolvimento da noção de espaço, pela criança, é anterior ao período em que a mesma frequenta a escola. Porém, é na escola em que se deve trabalhar com a aprendizagem espacial voltada para a compreensão das formas que a sociedade organiza o espaço. Castrogiovanni (2008) reflete que é primordial que no ensino da Geografia, o aluno seja capaz de fazer uma avaliação crítica de mapas, e seja capaz de decodificar e transpor os dados para seu cotidiano.

Caminhos de Geografia Uberlândia-MG $\quad$ v. 22, n. $83 \quad$ out./2021 p. 144-159 Página 146


Discussão do lugar e alfabetização cartográfica no ensino fundamental: a elaboração de cadernos didáticos associados a Atlas Geoambientais municipais do Centro Oeste Gaúcho
Franciele Delevati Ben

Giorge Gabriel Schnorr Carina Petsch Anderson Augusto Volpato Sccoti Luis Eduardo de Souza Robaina Romario Trentin

Para Breda (2017) considera a "Alfabetização Cartográfica" como um processo voltado para o domínio das técnicas de mapeamento, contribuindo para o entendimento da codificação e decodificação dos mapas. Já Letramento Cartográfico, a autora ressalta que é a função social das representações, que ao mesmo tempo engloba e ultrapassa o processo de alfabetização. Castellar e Vilhena (2010), também diferenciam os dois conceitos:

\begin{abstract}
Alfabetizar, segundo o dicionário Aurélio, é ensinar a ler [...] ensinar a ler geografia significa criar condições para que a criança leia o espaço vivido, utilizando a cartografia como linguagem para que haja o letramento geográfico. Ensinar a ler o mundo é um processo que se inicia quando a criança reconhece os lugares e os símbolos dos mapas, conseguindo identificar as paisagens e os fenômenos cartografados e atribuir sentido ao que se está escrito. (CASTELLAR e VILHENA, 2010, p.123).
\end{abstract}

Seguindo essa abordagem, Richter (2017) aponta que o Letramento Cartográfico utiliza as práticas socioculturais dos alunos, para efetuar a leitura do mapa e associá-lo ao espaço vivido e cotidiano. Além de pensar na Cartografia Escolar, e no uso do Atlas para os alunos, também devemos nos preocupar com a capacidade do professor de compreender o uso do mapa na sala de aula. Castellar (2011) salienta que "é preciso que os professores compreendam os fundamentos teóricos da discussão cartográfica”. Ainda de acordo com Richter (2017) há alguns pontos que podem qualificar o trabalho com mapa, na aula de Geografia:

1) reconhecer a Cartografia como linguagem; 2) o mapa apresenta uma contribuição para além do espaço escolar; 3) o processo de alfabetização e letramento cartográfico precisam fazer parte do trabalho escolar de Geografia; 4) para a utilização do mapa nas aulas de Geografia é fundamental que ele esteja aliado aos próprios conteúdos geográficos; e 5) o mapa contribui significativamente para o processo de desenvolvimento do pensamento espacial e do raciocínio geográfico (RICHTER, 2017, p. 287).

Sendo assim, compreender alguns fundamentos da Cartografia escolar, o processo de Alfabetização Cartográfica e Letramento Cartográfico são indispensáveis para a compreensão dos produtos cartográficos do Atlas Geoambiental. Nesse sentido, salientamos que a elaboração do caderno didático, como recurso didático, é uma tentativa de auxiliar a compreensão dos mapas. E também é uma proposta que vai no sentido de tornar mais simples e atrativa a abordagem da Cartografia na aula de Geografia.

\title{
Conceituação de Atlas e seus tipos
}

Conceitualmente, os Atlas são conjuntos de mapas, o que difere cada um deles é a aplicação e principalmente a forma de aquisição das informações e análises possibilitadas por esses documentos, como é o caso dos Atlas Geoambientais que detém uma forma de elaboração específica. Os Atlas podem apresentar diversas funções, a mais comum e usual, é como um suporte ao ensino da Cartografia. Libault (1975), apresenta seis tipos distintos de Atlas: os Atlas de referência voltados ao registro de toponímias e contendo informações da topografia, enfatizando lugares; Atlas mistos, são modelos que além das toponímias e da topografia, apresentam mapas de vegetação, recursos naturais, áreas industriais; os Atlas especiais, evidenciam uma determinada temática; Atlas monográficos, onde se incluem os atlas nacionais, regionais e urbanos; Atlas de organização, voltados a fornecer subsídios para o planejamento; e finalizando, os Atlas escolares, que de forma didática devem evidenciar feições da paisagem física e humana.

Já Oliveira (1993), no dicionário Cartográfico, apresenta uma série de exemplos de Atlas, com diferentes temporalidades, mas cabe destacar os conceitos apresentados para: Atlas escolar, o qual é um produto utilizado como aporte no ensino de temas relacionados à geografia; e Atlas Geográfico, cujo as informações podem representar um conjunto de fenômenos de um determinado local, num período de tempo estabelecido. Nesse sentido, os Atlas geográficos escolares são instrumentos fundamentais no processo ensino/aprendizagem de Geografia e, para que cumpram seu papel, devem apresentar um design concernente com sua finalidade, ou seja, cada mapa do atlas deve ser

$\begin{array}{llllll}\text { Caminhos de Geografia } & \text { Uberlândia-MG } & \text { v. 22, n. 83 } & \text { out./2021 } & \text { p. 144-159 } & \text { Página } 147\end{array}$


Discussão do lugar e alfabetização cartográfica no ensino fundamental: a elaboração de cadernos didáticos associados a Atlas Geoambientais municipais do Centro Oeste Gaúcho
Anderson Augusto Volpato Sccoti

Luis Eduardo de Souza Robaina Romario Trentin

elaborado de forma que seus componentes sejam claramente distinguíveis, traduzidos com facilidade e com o mínimo de erro possível. (AGUIAR, 2018, p. 40).

A escala em que os Atlas são produzidos é muito variável, podendo abranger extensões espaciais e territoriais de continentes, países, estados, regiões e municípios, apresentando ainda diferentes temporalidades (OLIVEIRA, 1993). Se tratando de Atlas municipais, temos um grande número de exemplos, destacamos aqui os trabalhos de Almeida (2003); Batista e Valente (2014); Romig e Pitano (2020).

Romig e Pitano (2020, p. 245), definem que:

O atlas municipal é composto por mapas, imagens, gráficos, tabelas e conteúdos escritos que se referem à história, população, economia, características físicas e paisagens de determinado município. Isso tende (ainda que não garanta) a promover um ensino interativo e uma aprendizagem dinâmica, na qual o aluno tem a possibilidade de ler o espaço empiricamente vivenciado, observá-lo e melhor entendê-lo (Romig e Pitano, 2020, p. 245).

Um exemplo de Atlas municipal, que apresenta um forte potencial voltado ao ensino, são os Atlas Geoambientais, os quais se diferenciam dos demais tipos de Atlas, por apresentar uma proposta metodológica específica, baseada no mapeamento dos componentes do ambiente e em uma posterior correlação sistêmica dos atributos físicos e antrópicos, gerando como produto um mapa síntese, denominado geoambiental. Corroborando com Libault (1975), o Atlas Geoambiental pode ser caracterizado como um "Atlas especial". Conforme Herrmann (2004), o termo geoambiental, baseiase na segmentação de classes hierarquizadas do ambiente, para a descrição dos sistemas e unidades geoambientais, é necessário conhecer e mapear atributos do relevo, fitogeográficos e antrópicos.

Dentro dessa ótica, Robaina et al. (2014), discute que os Atlas Geoambientais têm como enfoque a determinação de diversos temas os quais compõe a paisagem, através da análise integrada dos componentes, utilizando as ferramentas da cartografia, é possível traçar as vulnerabilidades e aptidões, visando o desenvolvimento regional. A cartografia é um ponto chave no processo de elaboração dos estudos geoambientais e consequentemente na obtenção dos Atlas. Para Vedovello (2004), a cartografia geoambiental pode ser entendida como o processo envolvido na obtenção, análise, representação, comunicação e aplicação de dados e informações do meio físico, analisando e descrevendo as potencialidades e fragilidades do terreno, assim como os perigos, riscos, impactos e conflitos decorrentes da relação sociedade e natureza. Os produtos da cartografia geoambiental, são materializados através dos zoneamentos, os quais apresentam um caráter técnico, voltado às ações de planejamento e ordenamento do espaço geográfico e os Atlas, que apresentam um cunho mais didático e são voltados às ações educativas.

Para Menezes e Robaina (2015), a educação moderna, não vislumbra apenas que o aluno tenha capacidade de decorar e memorizar os conteúdos, como agentes descontextualizados do mundo que habitam, mas sim formar cidadãos com capacidade de entender seu entorno e discuti-lo de forma crítica, agindo positivamente em sociedade. Os estudos Geoambientais, apresentam uma discussão ampla que pode ser aplicada em vários setores da sociedade, mas se tratando do Atlas Geoambiental, esse por sua vez apresenta um forte potencial didático, configurando um recurso ímpar, que pode aplicado com fins educacionais, promovendo a difusão de um conhecimento baseado na dialética. 
Discussão do lugar e alfabetização cartográfica no ensino fundamental: a elaboração de cadernos didáticos associados a Atlas Geoambientais municipais do Centro Oeste Gaúcho
Anderson Augusto Volpato Sccoti Luis Eduardo de Souza Robaina Romario Trentin

Dessa forma, os Atlas Geoambientais municipais permitem que o aluno possa desenvolver a compreensão cartográfica do local, possa desenvolver a relação que existe entre os produtos cartográficos, que nos livros didáticos geralmente utilizam escalas nacionais e eventualmente escalas estaduais, para uma compreensão do seu município. Poder visualizar o seu ambiente local, onde diariamente convive com esta paisagem, relevo, ocupação do espaço possibilita ao aluno a compreensão da importância que cada atividade econômica desenvolvida no município, cada forma de relevo, tipo de rocha, solo, trabalhado nas disciplinas de geografia, não são fruto de um mundo abstrato, mas estão presentes no seu cotidiano e contribuem para o desenvolvimento local.

\section{MATERIAIS E MÉTODOS}

O artigo em questão é baseado em um método descritivo sobre a metodologia de elaboração de cadernos didáticos associados a Atlas Geoambientais. A linguagem utilizada no caderno didático foi mais informal e simples, buscando facilitar e aproximar os professores e alunos das atividades. $O$ processo de elaboração do Atlas Geoambiental pode ser observado nos trabalhos de Robaina et al. (2014); Robaina e Menezes (2015); Robaina; Trentin; Menezes (2019). Até o momento, foram produzidos três cadernos didáticos, sendo estes associados aos Atlas Geoambientais dos municípios de Manoel Viana, São Francisco de Assis e São Vicente, todos localizados no estado do Rio Grande do Sul.

\section{Organização do Caderno didático}

Como o caderno didático é voltado para professores e alunos da educação básica, foi adotada uma estrutura de organização, seguida para cada uma das atividades, baseada em Passini (2012). Os itens inseridos, em ordem de apresentação foram:

- $\quad$ Assuntos que podem ser trabalhados utilizando essa atividade: procurando estabelecer relações com assuntos da BNCC (BRASIL, 2018);

- Materiais que serão utilizados: elucidando ao professor o material que é necessário para aplicação da atividade;

- $\quad$ Procedimentos para o professor: uma explicação para o professor sobre a execução da atividade e formas de conduzir a atividade, apresentando possíveis discussões e interpretações que poderiam ser feitas;

- $\quad$ Procedimentos para o aluno: explicações dos jogos e atividades para os alunos entenderem como funciona a dinâmica;

- Avaliação: destinado ao professor, exemplificando como avaliar os alunos com base nos questionamentos apresentados durante a realização das atividades.

\section{Elaboração das atividades do caderno didático}

Os cadernos didáticos foram construídos para fomentar a leitura e interpretação do espaço por alunos de educação básica, e foi baseado no método de Alfabetização Cartográfica proposto por Simielli (1999), para tornar o aluno um mapeador consciente e um leitor crítico (Figura 01). Foram elaboradas 6 atividades dentro da lógica de Simielli (1999), onde quatro delas são especialmente destinadas para fazer do aluno um leitor crítico: batalha latitudinal, jogo da escala, jogo geossistêmico e tutorial do Google Earth (GE). E duas das atividades são voltadas para a formação do aluno mapeador consciente: mapas mentais e maquete.

Caminhos de Geografia Uberlândia-MG $\quad$ v. 22, n. $83 \quad$ out./2021 $\quad$ p. 144-159 Página 149


Franciele Delevati Ben Giorge Gabriel Schnorr Carina Petsch

Discussão do lugar e alfabetização cartográfica no ensino fundamental: a elaboração de cadernos didáticos associados a Atlas Geoambientais municipais do Centro Oeste Gaúcho
Anderson Augusto Volpato Sccoti Luis Eduardo de Souza Robaina Romario Trentin

Figura 01 - Metodologia utilizada para elaboração da sequência de seis atividades do caderno didático.

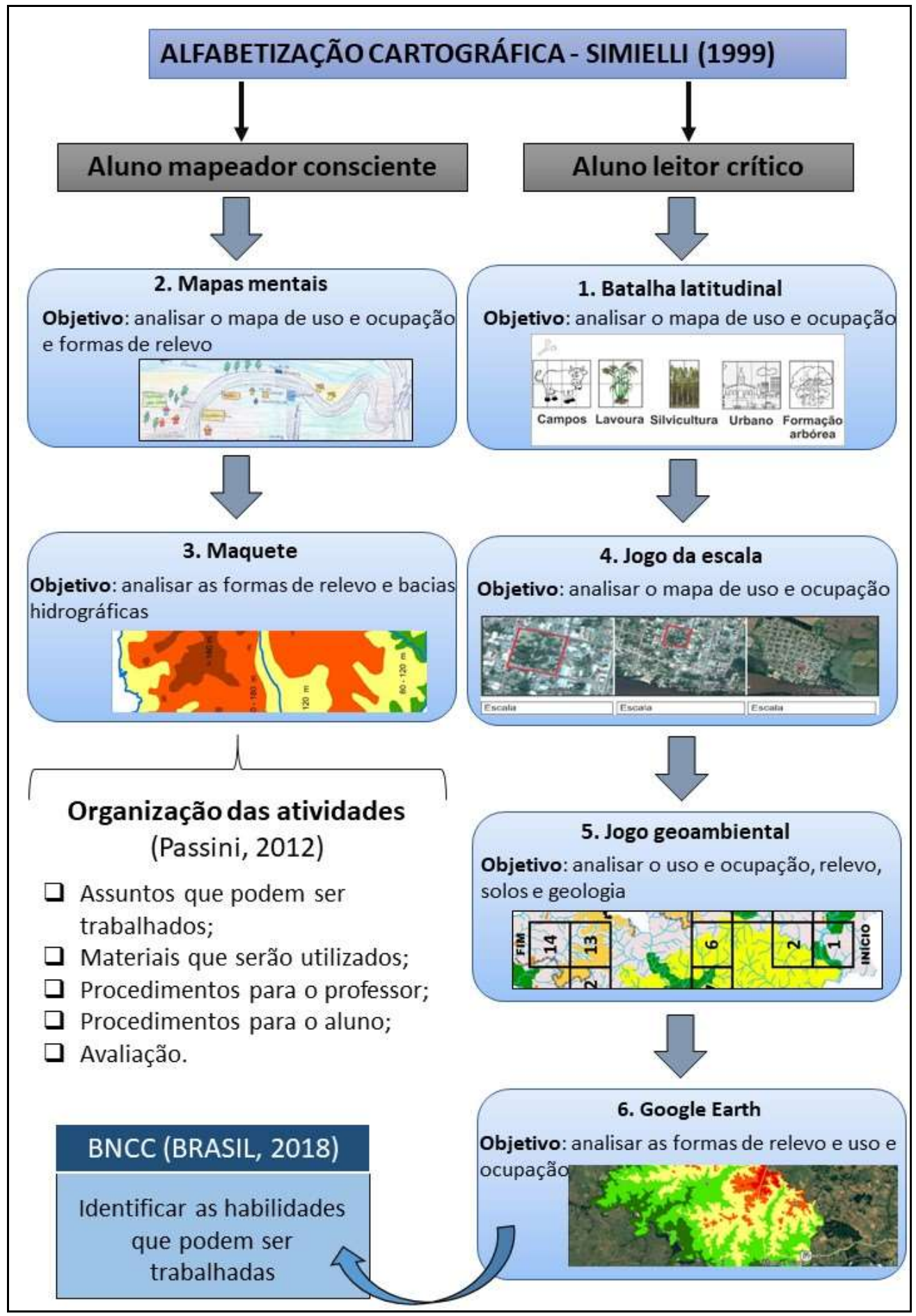

Fonte - Autores (2020).

O tutorial do GE foi inserido como um suporte para que o professor possa trabalhar com geotecnologias na sala de aula. Os arquivos dos mapas de uso do solo, hipsometria e declividade foram transformados em formato .kml e estão disponíveis no site do referido laboratório que produz os Atlas Geoambientais. O tutorial possui as seguintes etapas: busca do instalador e download do 
Discussão do lugar e alfabetização cartográfica no ensino fundamental: a elaboração de cadernos didáticos associados a Atlas Geoambientais municipais do Centro Oeste Gaúcho
Franciele Delevati Ben Giorge Gabriel Schnorr Carina Petsch Anderson Augusto Volpato Sccoti Luis Eduardo de Souza Robaina Romario Trentin

GE, instalação do aplicativo, como inserir o arquivo .kml no GE, como deixar disponível somente algumas classes do mapa e como traçar um perfil topográfico.

As atividades serão correlacionadas com as habilidades que a BNCC (BRASIL, 2018) propõe que sejam desenvolvidas na área da Geografia, e indicadas ao professor as séries em que o caderno didático pode ser aplicado. Ressalta-se também que as atividades aqui detalhadas podem ser adaptadas de acordo com o contexto do professor, e também podem ser desenvolvidas em projetos interdisciplinares com a área da Matemática, História e Ciências, por exemplo. Além disso, é necessário que os alunos tenham acesso a versão impressa ou digital dos Atlas Geoambientais, para aplicação das atividades dos cadernos didáticos.

\section{RESULTADOS: DESCRIÇÃO DAS ATIVIDADES PROPOSTAS}

A atividade 1, foi chamada de Batalha Latitudinal, com o objetivo de trabalhar com o aluno o mapa de uso e ocupação da terra e o conceito cartográfico de coordenadas. A lógica deste jogo é a mesma do original, chamado de "Batalha Naval". São disponibilizadas figuras de uso da terra correspondendo às lavouras, campos, silvicultura, área urbana e formação arbórea, que no jogo original seriam os navios que serão distribuídas para os jogadores. O mapa será o tabuleiro que está dividido em quadrículas onde as figuras de uso da terra se encaixam, sendo assim, para aplicar o jogo em sala de aula o professor não necessita realizar nenhuma alteração. A avaliação proposta se baseia na discussão e debate desenvolvidos ao longo da atividade, sendo as questões propostas: "Será que antigamente havia mais áreas com florestas? O que é plantado nas áreas de areais do município? O clima influencia na plantação da cultura de arroz?"

A atividade 2, denominada de mapas mentais, tem o objetivo de trabalhar com o aluno o mapa de uso e ocupação da terra e base econômica do Brasil e RS. Ao elaborar o mapa mental de lugares conhecidos do município e interpretar o mapa de uso e ocupação da terra o aluno poderá compreender quais são as principais atividades econômicas desenvolvidas. Com o auxílio do livro didático é possível estabelecer essas discussões sobre a base econômica em outras escalas, como a estadual ou a nacional. A proposta do exercício é fazer com que o aluno coloque em prática os conhecimentos presentes sobre seu município, de tal forma a observar e reconhecer detalhes e mapeá-los. Após o mapeamento do seu espaço de vivência, o aluno é estimulado a entender como seu mapa mental se relaciona e está inserido no mapa de uso e ocupação da terra em seu município. A avaliação proposta se baseia na discussão desenvolvida ao longo da atividade, sendo as questões propostas: "Reunir os alunos em um grande grupo onde eles podem desenhar o que aprenderam e criar a legenda. Realizar questionamentos sobre as bases econômicas do município e culturas predominantes. Analisar as dificuldades em desenvolver o mapa e se há necessidade de esconder algumas coisas citadas."

$\mathrm{Na}$ atividade 3, onde é proposto o exercício de confecção de uma maquete, foi disponibilizado um modelo, onde são inseridos os limites de corte para sobreposição das camadas, com as classes de altitude, representadas em cores frias (porções mais baixas) e quentes (áreas com maior altitude), além dos principais canais de drenagem. Nessa atividade, o professor trabalhará com os alunos, os conceitos ligados a diferenças topográficas e características do relevo, bem como as principais direções em que a drenagem do município escoa, chegando ao conceito de bacias hidrográficas. Ao executar essa atividade o aluno desenvolverá habilidades voltadas ao entendimento das diferentes altitudes do município e compreender a organização da rede de drenagem. A avaliação sugerida para esta atividade é a elaboração da maquete, sempre levando em consideração o desenvolvimento da legenda e a localização de fotografias do atlas geoambiental que podem ser avaliadas, assim como análises e correlações feitas pelos alunos.

A atividade 4, nomeada como jogo da escala, se baseia em o aluno escolher um local da sua cidade, e com o auxílio do Google Earth, acompanhar a proporção de redução utilizada no mapa, através da ferramenta de zoom. Essa atividade se relaciona com a definição de escala e apresenta que a medida que se aumenta o detalhe da observação se perde a visão geral da cidade. Em conjunto com o professor de matemática, o aluno pode calcular o tamanho e a distância real dos objetos que está observando, utilizando a ferramenta de medição do Google Earth. A avaliação proposta é o cálculo da escala em três diferentes representações, que estão presentes no caderno didático.

$\begin{array}{lllll}\text { Caminhos de Geografia } \quad \text { Uberlândia-MG } & \text { v. 22, n. 83 } & \text { out./2021 } & \text { p. 144-159 Página } 151\end{array}$


Franciele Delevati Ben Giorge Gabriel Schnorr Carina Petsch

Discussão do lugar e alfabetização cartográfica no ensino fundamental: a elaboração de cadernos didáticos associados a Atlas Geoambientais municipais do Centro Oeste Gaúcho
Anderson Augusto Volpato Sccoti Luis Eduardo de Souza Robaina Romario Trentin

O tutorial do GE mostra o passo a passo para a instalação do aplicativo no computador, este que é necessário para realização da atividade 4. No GE, é possível executar os temas desejados, em arquivos no formato *kml. Os alunos além de poderem manipular e visualizar os mapas de hipsometria e declividade, é possível traçar perfis topográficos sobre o terreno e entender a configuração do terreno. Quanto ao mapa de uso e ocupação da terra, os alunos poderão além de visualizar o mapa, utilizar o modo de fotografias e o Google Street View, quando disponível, para ter interação com diferentes pontos do município.

A atividade 5, foi denominada jogo geoambiental e possui o objetivo de trabalhar variados assuntos: escala, uso da terra e solo do município, geologia e intemperismo. Nesse jogo é disponibilizado a figura do tabuleiro de unidades de relevo do município (Figura 2-) para ser impressa. A proposta do jogo é que os alunos ao jogarem o dado percorrem o número de casas sorteadas, encontrando assim, informações e instruções ambientais indicando o que fazer em relação ao jogo. Sendo assim o aluno vai entendendo o significado e importância de cada porção do município. A avaliação proposta pode ser baseada nas perguntas e discussões realizadas durante o jogo.

Figura 2- Manoel Viana (RS): Material cartográfico que está disponibilizado no caderno didático e que será utilizado pelos professores e alunos no processo de alfabetização cartográfica e representação/leitura do espaço do município. Os números utilizados nos produtos cartográficos correspondem à atividade que pertencem: 1 -

tabuleiro e opções de uso e ocupação do jogo batalha latitudinal; 3 - base para elaboração da maquete; 4 fragmentos de imagens utilizadas no jogo das escalas; 5 - tabuleiro utilizado no jogo Geoambiental.

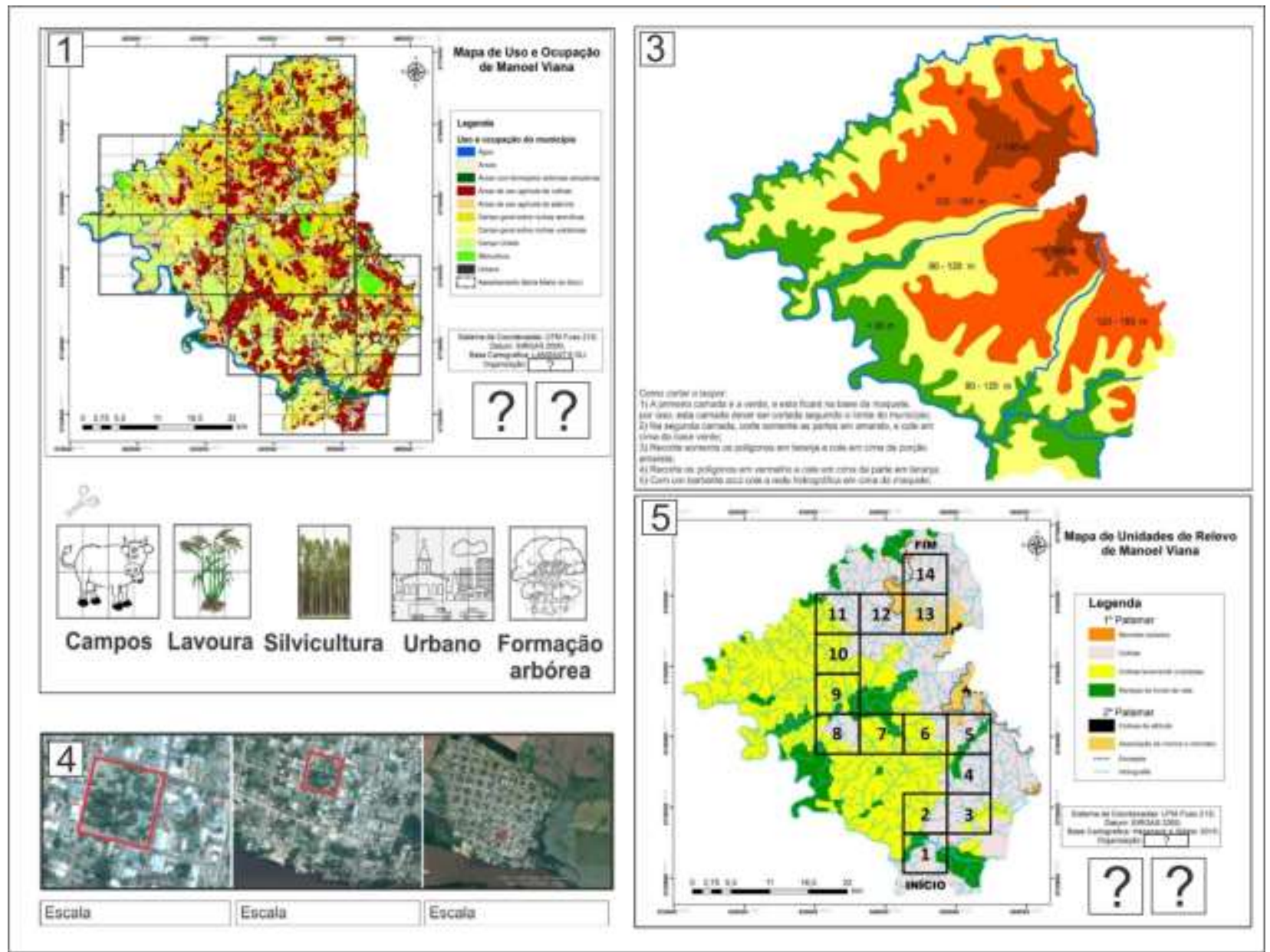

Fonte - Autores (2020).
Caminhos de Geografia
Uberlândia-MG
v. 22, n. 83
out./2021
p. 144-159
Página 152 
Discussão do lugar e alfabetização cartográfica no ensino fundamental: a elaboração de cadernos didáticos associados a Atlas Geoambientais municipais do Centro Oeste Gaúcho
Franciele Delevati Ben Giorge Gabriel Schnorr Carina Petsch Anderson Augusto Volpato Sccoti Luis Eduardo de Souza Robaina Romario Trentin

\section{DISCUSSÕES}

\section{Associação do caderno didático com as habilidades e competências propostas pela BNCC no ensino fundamental}

O estudo de cunho sistêmico, com destaque para as análises geoambientais, são ferramentas de grande importância para o estudo das dinâmicas da natureza, no momento que possibilitam o entendimento integrado, ou seja, todos os componentes de um sistema natural são interligados, quando ocorre a ruptura ou alteração do sistema, todos os componentes têm suas dinâmicas alteradas. O conhecimento dos sistemas, comuns ao cotidiano das pessoas, possibilita o conhecimento aprofundado do lugar e consequentemente sua valorização.

Nesse sentido, a elaboração de Atlas Municipais desempenha um papel fundamental, no estudo da Geografia voltada para a escala local, além de auxiliar os alunos no processo de alfabetização Cartográfica. Para o ensino fundamental a BNCC (BRASIL, 2018) afirma que "Ao tratar do conceito de espaço, estimula-se o desenvolvimento das relações espaciais topológicas, projetivas e euclidianas, além do raciocínio geográfico, importantes para o processo de alfabetização cartográfica e a aprendizagem com as várias linguagens (formas de representação e pensamento espacial)." Simielli (1999) sobre a alfabetização cartográfica cita que é possível trabalhar com o eixo do aluno leitor crítico e o eixo do mapeador consciente com encaminhamentos paralelos. $E$ que ambos eixos eliminam a possibilidade de desenvolver um aluno copiador de mapas.

Dessa forma, uma das primeiras habilidades que podem ser desenvolvidas com o uso do caderno didático aborda exatamente sobre a questão do espaço de vivência. A habilidade do segundo ano do Ensino Fundamental (EF02GE09), trata sobre a identificação de objetos e lugares de vivência, como a escola e local de moradia, em imagens aéreas e mapas (visão vertical) e fotografias (visão oblíqua). A atividade 2 que trata da elaboração de mapas mentais pelos alunos, pode auxiliar no desenvolvimento dessa habilidade na medida em que os alunos irão representar o mapa mental na visão vertical ou oblíqua, enquanto no dia-a-dia teremos uma visão horizontal. A habilidade EF02GE08, trata especificamente da elaboração do mapa mental. A BNCC deixa claro que os estudantes devem identificar e elaborar diferentes formas de representação (desenhos, mapas mentais, maquetes) para representar componentes da paisagem dos lugares de vivência. Segundo Pissinati e Archela (2007) o mapa mental é fundamental para conhecer o nível de percepção que os alunos possuem do espaço e a capacidade de representar o espaço real no papel. A atividade 3 sobre as maquetes, também pode ser desenvolvida na segunda série do ensino fundamental. Nesse sentido, pode ser elaborada de uma forma simples, fomentando discussões sobre os locais mais altos, os mais baixos e como a água da precipitação da chuva, irá se escoar nesse relevo.

Nesse contexto, a habilidade EF02GE11, também do segundo ano, aborda que é necessário "Reconhecer a importância do solo e da água para a vida, identificando seus diferentes usos (plantação e extração de materiais, entre outras possibilidades) e os impactos desses usos no cotidiano da cidade e do campo." A atividade 1 - Batalha Latitudinal - que é desenvolvida com os diferentes tipos de uso e ocupação da terra, pode ser inserida para desenvolvimento dessa habilidade. $\mathrm{O}$ aluno pode ser estimulado a inserir as figuras de uso da terra (Figura 02) sob o mapa dessa temática e visando a alfabetização cartográfica do aluno, discussões sobre localização, vizinhança, orientação pode ser estimuladas. $O$ professor pode utilizar uma abordagem sistêmica para explicar aos educandos os impactos negativos, que determinadas ações podem causar ao ambiente, por exemplo: o uso inadequado de agrotóxicos pode poluir os canais de drenagem, como consequência se tem a morte dos peixes e, consequentemente, falta de alimento para outros animais; outro exemplo é a retirada da floresta, esta ação deixa o solo desprotegido e vulnerável a erosão acelerada.

No terceiro ano, segundo a BNCC (BRASIL, 2018) uma das habilidades a serem desenvolvidas nos alunos é "Reconhecer e elaborar legendas com símbolos de diversos tipos de representações em diferentes escalas cartográficas. " correspondente ao código EF03GE07. Ao elaborar as atividade $2 \mathrm{e}$ 3 , que correspondem ao mapa mental e a maquete, ambas estruturadas dentro da lógica do aluno mapeador consciente, o professor de Geografia pode estimular a construção da legenda, ainda que os alunos representem os objetos de seu mapa com signos (símbolos) de forma similar ao que é visto no seu cotidiano. Archela e Thery (2008) definem que o signo (símbolo) é constituído por significante

$\begin{array}{lllll}\text { Caminhos de Geografia } \quad \text { Uberlândia-MG } & \text { v. 22, n. 83 } & \text { out./2021 } & \text { p. 144-159 Página } 153\end{array}$


Discussão do lugar e alfabetização cartográfica no ensino fundamental: a elaboração de cadernos didáticos associados a Atlas Geoambientais municipais do Centro Oeste Gaúcho
Franciele Delevati Ben Giorge Gabriel Schnorr Carina Petsch Anderson Augusto Volpato Sccoti Luis Eduardo de Souza Robaina Romario Trentin

(mensagem acústica) e significado (conceito). Por exemplo, ainda que as árvores sejam desenhadas com seu aspecto observado no cotidiano do aluno, é importante que o mesmo entenda a importância de sempre incluir todos itens na legenda. Simielli (1999) aponta que com os elementos de linhas, pontos e áreas, definidos como o alfabeto cartográfico, que objetos do mundo real que se tornarão representações no plano bidimensional.

Nessa etapa, também é importante realizar discussões mais simples sobre o alfabeto cartográfico, estimulando a abstração do aluno, para entender que as informações reais são representadas segundo as formas de linhas, polígonos e pontos. O aluno precisa entender a aplicação do alfabeto cartográfico na representação dos objetos, segundo Simielli (1999, p. 100) um exemplo está em um mapa onde temos: "a montanha (ponto), a estrada (linha) e a lagoa (área)". Nos mapas presentes no caderno didático, os dados de rede de drenagem representam a implantação linear e os dados de diferentes usos da terra e unidades de relevo são implantados em polígonos.

Além da construção da legenda, o professor pode debater com os alunos as legendas dos mapas já prontos para que assim entendam a espacialização dos dados. Conforme Archela (1999) debate, é importante identificar a variável visual utilizada para representar determinada informação, e seu modo de implantação. A atividade 2, mapa mental, recomendamos que seja desenvolvida em parceria com o (a) professor (a) responsável pela disciplina de Artes e que sejam desenvolvidas duas habilidades: "explorar e reconhecer elementos constitutivos das artes visuais (ponto, linha, forma, cor, espaço, movimento etc.) - código EF15AR02 - visto que os pontos, linhas e formas também fazem parte do alfabeto cartográfico; e a habilidade de "identificar e apreciar formas distintas das artes visuais tradicionais e contemporâneas, cultivando a percepção, o imaginário, a capacidade de simbolizar e o repertório imagético - código EF15AR01 - visto que os mapas mentais além de contribuírem na compreensão e representação do espaço vivido, estimulam a percepção, imaginação e a capacidade de construir símbolos que é fundamental para a construção da legenda.

Na BNCC no sexto ano deve ser trabalhada a habilidade EF06GE10, que trata de "Explicar as diferentes formas de uso do solo (rotação de terras, terraceamento, aterros etc.) e de apropriação dos recursos hídricos (sistema de irrigação, tratamento e redes de distribuição), bem como suas vantagens e desvantagens em diferentes épocas e lugares", onde é possível se trabalhar com a atividade 5 , o jogo geoambiental, que se volta no entendimento de aspectos como relevo, solos e uso e ocupação da terra. A atividade 5 foi criada para trabalhar com a percepção do aluno utilizando um tabuleiro que simula uma caminhada real pelo seu município. Para isso, elementos visuais foram inseridos como "contemple a paisagem, visto que você chegou ao ponto mais alto de seu município" e elementos de percepção, como a dificuldade da caminhada com o intuito de facilitar o entendimento da variação de declive e relevo, como por exemplo: "Agora que atravessou o Rio lbicuí você terá de se esforçar um pouco mais, pois irá para uma área um pouco mais alta que a anterior. Enquanto descansa, não jogue nessa rodada.".

Além disso, a atividade 5 proporciona duas diferentes estratégias de aprendizado, uma onde a interpretação sistêmica é estimulada, onde se apresenta a relação entre a hidrografia, relevo, solos, geologia e uso e ocupação, como por exemplo: "Nessa casa você deve tomar cuidado, temos área de fundo de vale e colinas levemente onduladas, onde em épocas de precipitação o leito do rio pode avançar deixando, assim, parte das planícies inundadas. Cuidado! Avance uma casa". É outra forma onde o aluno é estimulado a pesquisar no Atlas Geoambiental, para avançar no jogo: "Nesta casa vá devagar e tente desviar os rios e morrotes no caminho que podem atrasar seu trajeto. Volte uma casa e procure no Atlas o que são Morrotes e conte para os colegas".

No contexto da BNCC (BRASIL, 2018) no sexto ano a habilidade EF06GE08 refere-se a "Medir distâncias na superfície pelas escalas gráficas e numéricas dos mapas". A atividade 4 se trata do jogo das escalas, e pode ser trabalhada de maneira interdisciplinar com o professor de Matemática, visando desenvolver a habilidade EF06MA24, que trata sobre "Resolver e elaborar problemas que envolvam as grandezas de comprimento...", visto que a partir do quinto ano eles aprenderam sobre a transformação de medidas, o que é fundamental para trabalhar com o exercício de proporção entre a superfície real e a representada. O exemplo apresentado no caderno didático trata da redução de terrenos referentes às praças centrais dos municípios de São Vicente do Sul, Manoel Viana e São Francisco de Assis. A atividade deve ser realizada em conjunto com a atividade 6, referente ao uso do Google Earth, para que seja possível realizar as medidas reais dos terrenos. Essa atividade também vai ao encontro do que é teorizado na BNCC (BRASILI, 2018) sobre as séries finais do

$\begin{array}{lllll}\text { Caminhos de Geografia } \quad \text { Uberlândia-MG } & \text { v. 22, n. } 83 & \text { out./2021 } & \text { p. 144-159 } & \text { Página } 154\end{array}$


Discussão do lugar e alfabetização cartográfica no ensino fundamental: a elaboração de cadernos didáticos associados a Atlas Geoambientais municipais do Centro Oeste Gaúcho
Franciele Delevati Ben Giorge Gabriel Schnorr Carina Petsch Anderson Augusto Volpato Sccoti Luis Eduardo de Souza Robaina Romario Trentin

ensino fundamental onde o aluno ao desenvolver a análise em diferentes escalas, possa ter a capacidade não apenas de visualização, "mas que relacionem e entendam espacialmente os fatos e fenômenos, os objetos técnicos e o ordenamento do território usado” (BRASIL, 2018, p.383).

Ainda no sexto ano a BNCC (BRASIL, 2018) aponta como uma das habilidades a serem desenvolvidas "Elaborar modelos tridimensionais, blocos-diagramas e perfis topográficos e de vegetação, visando à representação de elementos e estruturas da superfície terrestre", referente ao código EF06GE09. Aqui recomendamos que a atividade 3, da maquete, seja desenvolvida para que os alunos entendam o conceito de imagem bidimensional e tridimensional. Além disso, a alfabetização cartográfica dos alunos pode ser promovida com a realização da atividade 6 , onde podem ser traçados perfis topográficos mostrando a variação de altitude do terreno. Ao navegar no GE, o aluno tem a possibilidade de desenvolver a visão vertical e oblíqua do terreno, que pode ser associada à atividade da maquete também.

A atividade 6, referente ao uso do GE pode ser desenvolvida em vários momentos do ensino fundamental, pois se encaixa em uma das competências específicas a serem desenvolvidas nesse período, segundo a BNCC (BRASIL, 2018, p. 368) "Desenvolver o pensamento espacial, fazendo uso das linguagens cartográficas e iconográficas, de diferentes gêneros textuais e das geotecnologias para a resolução de problemas que envolvam informações geográficas". Ressaltamos também que a visualização dos mapas (formato de arquivo *.kml) no Google Earth ajuda a desenvolver a noção espacial de continuidade, ou seja, fomenta a noção de vizinhança e orientação ao entender que há outros municípios que fazem limite com o seu.

\section{Dificuldades na leitura e interpretação dos produtos cartográficos do Atlas Geoambiental}

Segundo Carreiro (2003), é preciso detalhar os temas utilizados em materiais de suporte didático, para que no momento em que outros professores se utilizem desse material, compreendam os procedimentos utilizados na sua elaboração. Sendo assim, este item será desenvolvido pautado nas principais dificuldades que professores podem encontrar ao interpretar os mapas que fazem parte das atividades do caderno didático.

As maiores dificuldades enfrentadas por professores e alunos, ao se utilizarem das ferramentas e dos produtos da cartografia, está materializado no entendimento da lógica das cores: cores frias (azul e verde) para eventos mais amenos e cores quentes (laranja e vermelho) para fenômenos ímpares. Um clássico exemplo desses jogos de cores, pode ser observado nos mapas hipsométricos, onde cores frias representam porções de terreno menos elevadas em relação ao nível médio dos mares e cores quentes para porções com maiores altitudes. A legenda do mapa, indispensável ao entendimento de qualquer material cartográfico, auxilia na solução do problema citado. O conceito de elevação e uso de cores pode ser trabalhado utilizando a atividade 3, através do processo de elaboração da maquete do município.

O conceito de declividade, no caderno didático, foi explorado na atividade 5 que trata de uma simulação de trajeto de caminhada no município. Conforme já discutimos no item 5.1 , a declividade pode ser entendida pelos alunos como a variação de inclinação do terreno, que irá resultar em diferentes níveis de cansaço na sua caminhada. Ao ler o mapa de declividade no Atlas, o professor pode trabalhar com conceitos já vivenciados pelo aluno, por meio de palavras como "plano", "acidentado", "montanhoso" "barranco" que remetem justamente às transições de declividade, tornando menos difícil a abstração desse conceito. Aquilo que o aluno vê na legenda no mapa numa escala menor, pode ser materializada primeiramente observando terrenos próximos da escola e que se encaixam nessa variação do "plano ao montanhoso". Ainda nesse sentido, a atividade de elaboração da maquete, pode ajudar a desenvolver o conceito de declividade num modelo tridimensional.

O mapa pedológico, foi trabalhado de forma breve no jogo geoambiental, que corresponde a atividade 5 , onde foram inseridos aspectos básicos diferenciando solos mais argilosos de solos arenosos. As possíveis dificuldades que podem ser enfrentadas pelo professor ao abordar o mapa de solos, estão em explicar os diferentes tipos, o porquê de sua localização, bem como aspectos de profundidade, textura ou de fertilidade. Uma forma de discutir a localização de determinado tipo de solo pode ser feita avaliando mudanças no mapa de altitudes, declividades e geologia. Para entender aspectos de sua composição o professor pode trabalhar de forma mais lúdica, com um material arenoso e outro argiloso mostrando que há diferentes composições granulométricas dos solos e que sua gênese tem relação com as características da rocha matriz.

No que tange a interpretação e leitura do mapa de uso e ocupação da terra, o exercício 1 pode auxiliar neste processo visto que os alunos compreendem, através do uso de figuras lúdicas, que as áreas de campo e pastagens são ocupadas pelo gado, as áreas de lavoura podem ser de arroz, soja

$\begin{array}{lllll}\text { Caminhos de Geografia } \quad \text { Uberlândia-MG } & \text { v. 22, n. 83 } & \text { out./2021 } & \text { p. 144-159 Página } 155\end{array}$


Franciele Delevati Ben

Giorge Gabriel Schnorr

Carina Petsch

Discussão do lugar e alfabetização cartográfica no ensino fundamental: a elaboração de cadernos didáticos associados a Atlas Geoambientais municipais do Centro Oeste Gaúcho
Anderson Augusto Volpato Sccoti

Luis Eduardo de Souza Robaina Romario Trentin

ou milho, que a silvicultura está associada a plantação de eucaliptos, que a mata de encosta está associada a áreas de floresta e a área urbana corresponde a cidade. Além disso, a atividade sobre os mapas mentais, também estimula que o desenho representado pelos alunos seja comparado com as classes de uso e ocupação da terra, em outra escala. E por fim, a atividade utilizando o GE também auxilia na visualização dos diferentes tipos de uso da terra, visto que pode ser aplicado um maior nível de zoom para identificação destas classes.

Todos os mapas até agora descritos, sendo eles de hipsometria, declividade, pedológico e uso e ocupação da terra, representam dados que de fato são reais no seu cotidiano, ou seja, diferenças de declividade, altitude, solos e usos da terra podem ser visualizados e no caso do relevo sentidos ao se deslocar no mapa. O mapa geoambiental, fruto da correlação de variáveis ambientais, não pode ser materializado para o aluno no ambiente. Neste sentido podemos dizer que a Cartografia de síntese apresenta maiores desafios no seu entendimento. O entendimento dos fenômenos de maneira sistêmica, ou seja, a relação dialética entre os componentes do ambiente, pode parecer em algumas situações, algo de difícil concepção, pois é necessário em alguns casos trabalhar com situações que não estão visíveis aos olhos dos alunos, a maneira mais simples para que os discentes entendam o ambiente de forma sistêmica, ocorre através do conhecimento prévio das partes, da Cartografia Analítica do Atlas Geoambiental, ou seja, conhecer os componentes e só então iniciar a explicação do "todo" (geoambiental), tal sequência pode ser observada na própria metodologia de elaboração do mapeamento geoambiental (Figura 03). O caderno didático possibilita de maneira mais acessível aos alunos, desenvolverem uma visão sistêmica do lugar em que vivem.

Figura 03 - Atividades de 1 a 4 fomentam a alfabetização cartográfica e a análise espacial baseada em dados que são concretos no espaço vivido do aluno. O jogo geoambiental trabalha com um mapa com informações que precisam ser abstraídas pelo aluno. Portanto, é estimulada a correlação entre as variáveis, uso da percepção do ambiente e a visualização da paisagem.

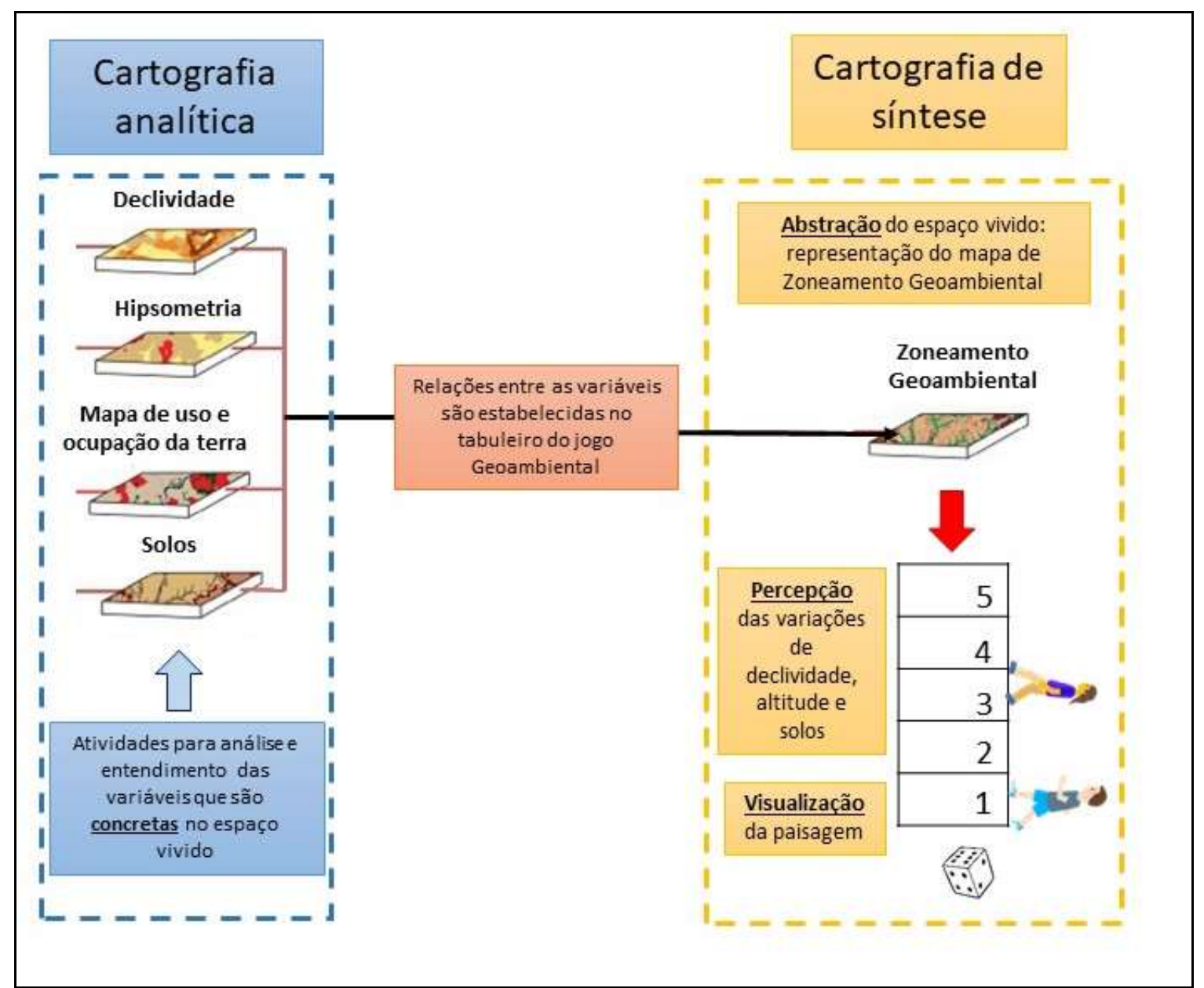

Fonte - Autores (2020).

Caminhos de Geografia Uberlândia-MG v. 22, n. $83 \quad$ out./202


Discussão do lugar e alfabetização cartográfica no ensino fundamental: a elaboração de cadernos didáticos associados a Atlas Geoambientais municipais do Centro Oeste Gaúcho
Franciele Delevati Ben

Giorge Gabriel Schnorr Carina Petsch Anderson Augusto Volpato Sccoti Luis Eduardo de Souza Robaina Romario Trentin

O GE apresenta-se como uma importante ferramenta para a aplicação na alfabetização cartográfica, pois possibilita desenvolver a orientação, conceito de escala, coordenadas, tipos de uso e ocupação, visão tridimensional, entre outros. Porém existem algumas limitantes para o uso desse programa, o primeiro é o acesso a um computador com internet, item básico, mas que muitas escolas não possuem disponível para os alunos, e as demais dificuldades estão associadas aos procedimentos de manejo do software, mas que podem ser minimizadas com o uso de tutoriais, como é o caso apresentado no caderno didático de Manoel Viana. Ressalta-se assim que é fundamental além de apontar quais são as funções que o GE possui, discutir o que pode ser trabalhado e debatido ao fazer, por exemplo um perfil topográfico.

\section{CONSIDERAÇÕES FINAIS}

A elaboração de Atlas Geoambientais em uma escala municipal proporciona ao professor o uso de um material que permite a compreensão do espaço vivido pelo aluno, utilizando o lugar como escala de análise geográfica. Além disso, permite que relações sejam estabelecidas com temas abordados em escalas regionais, estaduais e de todo o País, fomentando a correlação dos assuntos e a conexão das variáveis ambientais, que na natureza estão interligadas e a qualquer alteração que ocorre em uma, todo o sistema passa por modificações.

No que se refere a elaboração do caderno didático, este material mostra um grande potencial para viabilizar a discussão do conteúdo cartográfico contido no Atlas Geoambiental, assim como para se trabalhar com as competências e habilidades exigidas pela BNCC, sendo uma delas a alfabetização cartográfica dos alunos durante o ensino fundamental. Das seis atividades propostas no caderno didático, estas podem ser desenvolvidas com diferentes níveis de discussão, do segundo ao sexto ano do ensino fundamental e seguem os eixos propostos por Simielli (1999), desenvolvendo o aluno leitor crítico e o aluno mapeador consciente. Os cadernos didáticos se mostram como ferramentas de ensino a serem utilizadas em conjunto com o livro didático.

As atividades foram construídas para trabalhar com noções de lateralidade, vizinhança, orientação tipos de imagens, tipos de visões, legenda e alfabeto cartográfico, proporção e escala ao mesmo tempo em que fazem a leitura e análise dos mapas analíticos apresentados no Atlas Geoambiental. Além disso, as atividades dialogam com situações cotidianas, trazendo experiências e conceitos já anteriormente acomodados pelos alunos. A atividade do jogo geoambiental, simula uma caminhada real no município, onde o aluno é convidado a sentir o cansaço que mudanças de altitude e declividade impõe, bem como visualizar os aspectos geográficos a sua volta. $O$ jogo da batalha latitudinal ao mesmo tempo que proporciona a leitura do mapa de uso e ocupação da terra, já que o mesmo é o tabuleiro da atividade, de forma lúdica mostra as diferentes classes representadas por vacas, pés de arroz, eucaliptos e árvores. Sendo assim, o aluno leitor crítico ressignifica a legenda do mapa e reflete sobre o que é um campo, silvicultura ou uma mata de encosta.

Durante a elaboração do caderno didático, buscou-se considerar as dificuldades, que eventualmente podem ser enfrentadas, tanto pelo professor quanto pelo aluno, ao executar as atividades do caderno didático, as quais podem ser de ordem técnica e teórica. Todas as atividades apresentam uma explicação básica para o professor, de como orientar seus alunos, além da avaliação que pode ser elaborada. Além disso, possivelmente haverá muitas dificuldades para o entendimento do mapa de zoneamento geoambiental, visto que ele não é concreto no espaço vivido do aluno e demanda de abstração para seu entendimento. Para tanto é importante que a atividade 5, que aborda o mapa geoambiental, seja realizada somente no sexto ano, após a realização das atividades 1 a 4 que abordam a análise da Cartografia Analítica do Atlas Geoambiental, em outras séries do ensino fundamental.

\section{AGRADECIMENTOS}

Os autores agradecem o Fundo de Incentivo de Extensão da Universidade Federal de Santa Maria (FIEX/UFSM), pelo financiamento através de bolsas.

$\begin{array}{lllll}\text { Caminhos de Geografia } & \text { Uberlândia-MG } & \text { v. 22, n. } 83 & \text { out./2021 } & \text { p. 144-159 }\end{array}$


Discussão do lugar e alfabetização cartográfica no ensino fundamental: a elaboração de cadernos didáticos associados a Atlas Geoambientais municipais do Centro Oeste Gaúcho
Franciele Delevati Ben Giorge Gabriel Schnorr Carina Petsch Anderson Augusto Volpato Sccoti Luis Eduardo de Souza Robaina Romario Trentin

\section{REFERÊNCIAS}

AGUIAR, V. T. Navegar, com mapas, é bem mais preciso! In: ALMEIDA, R. D. de A. (org.) Novos rumos da Cartografia Escolar: currículo, linguagem e tecnologia. São Paulo: Contexto, 2018. p. 3756.

ALMEIDA, R. D. de. Cartografia Escolar. São Paulo: Contexto, 2007.

ALMEIDA, R.D de. Atlas municipais elaborados por professores: a experiência conjunta de Limeira, Rio Claro e Ipeúna. Cad. Cedes, v 23, n.60, p. 149 - 168, 2003. https://doi.org/10.1590/S0101$\underline{32622003000200003}$

ALMEIDA, R. D. de; PASSINI, E. Y. O espaço geográfico - ensino e representação. São Paulo: Contexto, 1994.

ALMEIDA, L.C. Do desenho ao mapa: iniciação cartográfica na escola. 4. ed. São Paulo: Contexto, 2006.

ARCHELA, R. S.; THÉRY, H. Orientação metodológica para construção e leitura de mapas temáticos. Confins, n. 3, p.1-21, 2008.

ARCHELA, R. S. Imagem e representação gráfica. Revista Geografia, v.8, n.1, p.5-11, 1999. https://doi.org/10.4000/confins.3483

BATISTA, N. L.; VALENTE, V. Atlas geográfico do município de Quevedos (RS). Revista Percurso NEMO, v. 6, n. 2, p. 121-140, 2014. https://doi.org/10.4025/revpercurso.v6i2.23412

BUENO, M. A; BUQUE, S. L. Cartografia Escolar e Atlas Escolares Municipais Brasil/Moçambique: o estudo do espaço local e a formação de professores. Revista Brasileira de Educação em Geografia, v. 7, n. 13, p. 233-247, 2017.

BRASIL. Ministério da Educação; Secretaria de Educação Básica; Conselho Nacional de Educação. Base nacional comum curricular: educação é a base. Brasília: MEC; SEB; CNE, 2018. Disponível em <http://basenacionalcomum.mec.gov.br/images/BNCC El EF 110518 versao final site.pdf>. Acesso em: 16 junho 2020.

BREDA, T. V. Por que eu tenho que trabalhar lateralidade?: experiências formativas com professoras dos anos iniciais. Tese (Doutorado em Ciência e Doutorado em Educação)-Campinas: Universidade Estadual de Campinas, Universidade Autónoma de Madrid. 2017.

CALLAI, H. C. A formação do profissional de Geografia: o professor. ljuí: Unijuí, 2013.

CALLAI, H. C. Aprendendo a ler o mundo: a geografia nos anos iniciais do ensino fundamental. Cad. Cedes, v. 25, n. 66, p. 227-247, 2005. https://doi.org/10.1590/S0101-32622005000200006

CASTELLAR, S. M. V. A alfabetização em geografia. Espaços da Escola, v. 10, n. 37, p. 29-46, 2000.

CASTELLAR, S. M. V; VILHENA, J. Ensino de Geografia: Coleção Ideias em Ação. São Paulo: Cengage Learning, 2010.

CASTELLAR. S. V. A cartografia e a construção do conhecimento em contexto escolar. In: ALMEIDA, R. D. Novos rumos da cartografia escolar - currículo, linguagem e tecnologia. São Paulo: Contexto, 2011, p.121-135.

CASTROGIOVANNI, A. C.; CALLAI, H. C.; KAERCHER, N. A. Ensino de Geografia: práticas e textualizações no cotidiano. Porto Alegre: Editora Mediação, 2008.

CARREIRO, M. S. A. Um olhar geográfico sobre a construção do Atlas municipal e escolar de Rio Claro. Cad. Cedes, v. 23, n. 60, p. 169 - 178, 2003. https://doi.org/10.1590/S0101$\underline{32622003000200004}$

CAVALCANTI, L. de S. Geografia e prática de ensino. Goiânia: Alternativa, 2002.

Propostas curriculares de Geografia no ensino: algumas referências de análise. Terra Livre, n. 14, p. 125-145, 1999.

$\begin{array}{lllll}\text { Caminhos de Geografia } \quad \text { Uberlândia-MG } & \text { v. 22, n. } 83 & \text { out./2021 } & \text { p. 144-159 } & \text { Página } 158\end{array}$


Discussão do lugar e alfabetização cartográfica no ensino fundamental: a elaboração de cadernos didáticos associados a Atlas Geoambientais municipais do Centro Oeste Gaúcho
Anderson Augusto Volpato Sccoti

Luis Eduardo de Souza Robaina

FRANCISCHETT, M. N. A Cartografia no ensino da Geografia: construindo os caminhos do cotidiano. Dissertação (Mestrado em Educação) - Guarapuava: UNICENTRO. 1997.

HERRMANN, M. L.P. Compartimentação Geoambiental da Faixa Central do Litoral Catarinense. In: V Simpósio de Nacional de Geomorfologia e I Encontro Sul- Americano de Geomorfologia. Santa Maria: Anais... 2004.

LIBAULT, A. A Geocartografia. São Paulo: Nacional/USP, 1975.

MARTINELLI, M. Um atlas geográfico escolar para o ensino-aprendizagem da realidade natural e social. Portal da Cartografia, v.1, n.1, p. 21-34, 2008.

OLIVEIRA, C. de. Dicionário Cartográfico. Rio de Janeiro: IBGE, 1993. 4ํed.

PASSINI, E. Y. Alfabetização cartográfica e a aprendizagem de geografia. São Paulo: Cortez, 2012.

PASSINI, E.Y.; R. PASSINI; S. T. ALYSZ, (org). Prática de ensino de geografia e estágio supervisionado. São Paulo: Contexto, 2007.

PASSINI, E. Y; CARNEIRO, S. M. M.; NOGUEIRA, V. Contribuições da alfabetização cartográfica na formação da consciência espacial-cidadã. Revista Brasileira de Cartografia, n. 66/4, 741-755, 2014.

PISSINATI, M. C.; ARCHELA, R. S. FUNDAMENTOS DA ALFABETIZAÇÃO CARTOGRÁFICA NO ENSINO DE GEOGRAFIA. Geografia, v. 16, n. 1, p.169-195, 2007.

RICHTER, D. A linguagem cartográfica no ensino de Geografia. Revista Brasileira de Educação em Geografia, v. 7, p. 277-300, 2017. https://doi.org/10.46789/edugeo.v7i13.511

ROBAINA, L. E. S; TRENTIN, R; MENEZES, D. J. Estudo do lugar a partir da série atlas municipal: bacia do Ibicuí, oeste do Rio Grande do Sul. Revista GEOUECE, v. 8, p. 207-221, 2019.

ROBAINA, L. E. SOUZA; MENEZES, DANIEL JUNGES. Valorização do estudo do lugar a partir do Atlas Geoambiental de São Pedro do Sul - RS. Geosaberes, v. 6, n.11, p. 60-71, 2015.

ROBAINA, L. E. S; TRENTIN, R.; ALVES, F. S; SCCOTI, A. A. V. Séries Atlas Municipais: Atlas geoambiental de Manoel Viana. Bagé: Ed. Urcamp, 2014.

ROMIG, K. L.; PITANO, S. C. O Atlas Geográfico Municipal como Recurso Didático no Ensino de Geografia: elaboração e perspectivas formativas. Geografia (Londrina) v. 29. n. 2. p. $241-260$, 2020. https://doi.org/10.5433/2447-1747.2020v29n2p241

SIMIELLI, M. E. R. Cartografia no Ensino Fundamental e Médio. In: CARLOS, A.F. (Org.). A geografia na sala de aula. São Paulo: Contexto, 1999. 1 ed.

VEDOVELLO, R. Aplicações da Cartografia Geoambiental. In: Simpósio brasileiro de Cartografia Geotécnica e Geoambiental. Anais... São Carlos, 2004.

Recebido em: 21/07/2020

Aceito para publicação em: 19/05/2021 